\title{
Mutational Analysis of Oncogenic AKT1 Gene Associated with Breast Cancer Risk in the High Altitude Ecuadorian Mestizo Population
}

\author{
Andrés López-Cortés ${ }^{(D)},{ }^{1}$ Paola E. Leone ${ }^{\mathbb{D}}{ }^{1}{ }^{1}$ \\ Byron Freire-Paspuel, ${ }^{2,3}$ Nathaly Arcos-Villacís, ${ }^{3,4}$ Patricia Guevara-Ramírez (D), \\ Felipe Rosales, ${ }^{5}$ and César Paz-y-Miño ${ }^{1}{ }^{1}$ \\ ${ }^{1}$ Centro de Investigación Genética y Genómica, Facultad de Ciencias de la Salud Eugenio Espejo, Universidad Tecnológica Equinoccial, \\ Avenue Mariscal Sucre, 170129 Quito, Ecuador \\ ${ }^{2}$ Escuela de Medicina, Facultad de Ciencias de la Salud, Universidad de las Américas, Avenue de los Granados, 170125 Quito, Ecuador \\ ${ }^{3}$ Departamento de Ciencias de la Vida, Universidad de las Fuerzas Armadas (ESPE), Avenue General Rumiñahui, \\ $1715231 B$ Sangolquí, Ecuador \\ ${ }^{4}$ The James Black Centre, Cardiovascular Division, King's College London, BHF Centre of Excellence, 125 Coldharbour Lane, \\ London SE5 9NU, UK \\ ${ }^{5}$ Departamento de Patología, Hospital Oncológico Solon Espinosa Ayala, Avenue Eloy Alfaro, 170138 Quito, Ecuador
}

Correspondence should be addressed to César Paz-y-Miño; cesar.pazymino@ute.edu.ec

Received 19 March 2018; Revised 17 May 2018; Accepted 30 May 2018; Published 3 July 2018

Academic Editor: Franco M. Buonaguro

Copyright (C) 2018 Andrés López-Cortés et al. This is an open access article distributed under the Creative Commons Attribution License, which permits unrestricted use, distribution, and reproduction in any medium, provided the original work is properly cited.

Breast cancer is the leading cause of cancer-related death among women worldwide. AKT1 encodes the kinase B alpha protein. The rs121434592, rs12881616, rs11555432, rs11555431, rs2494732, and rs3803304 single nucleotide polymorphisms have been identified in the AKT1 kinase gene. Activated AKT1 phosphorylates downstream substrates regulating cell growth, metabolism, apoptosis, angiogenesis, and drug responses. It is essential to know how breast cancer risk is associated with histopathological and immunohistochemical characteristics and genotype polymorphisms in a high altitude Ecuadorian mestizo population. This is a retrospective case-control study. DNA was extracted from 185 healthy and 91 affected women who live 2,800 meters above sea level. Genotypes were determined by genomic sequencing. We found a possible association between the noncoding intronic variant rs3803304 and breast cancer risk development: GG (odds ratio $[\mathrm{OR}]=5.2 ; 95 \%$ confidence interval $[\mathrm{CI}]=1.3-20.9 ; P \leq 0.05 ; Q>$ 0.05). Regarding pathologic characteristics, we found significant risk between estrogen receptor, progesterone receptor, and HER2 status and molecular subtypes $(P \leq 0.001 ; Q \leq 0.05)$. On the other hand, we did not find risk between variants and histopathological characteristics. Despite the small sample size, we found that the intronic variant, AKT1 rs3803304, may act as a predictive biomarker in the risk of developing breast cancer in the high altitude Ecuadorian mestizo population.

\section{Introduction}

Breast cancer $(\mathrm{BC})$ in women involves the progressive accumulation of genetic, hereditary, hormonal, and environmental factors representing a significant health problem worldwide [1]. BC is the leading cause of cancer-related death among women (521,541 cases) and the most commonly diagnosed cancer $(1,679,076$ cases) [2]. The areas with a higher incidence of BC per each 100,000 inhabitants are
Western Europe (89.9), Oceania (85.5), and Northern Europe (76.7), while South America has a lower incidence (44.3) [3]. In Ecuador, the incidence rate of $\mathrm{BC}$ has reached up to 32.7 in 2012 [4].

The molecular subtypification of the progesterone receptor (PR), estrogen receptor (ER), and HER2 status coupled with the histopathological classification (noninvasive or "in situ" carcinoma and invasive or infiltrating carcinoma) generates five different subtypes: luminal A (ER+ and/or 
$\mathrm{PR}+$, HER2-, or low Ki67), luminal B (ER+ and/or PR+, HER2+, or HER2- with high Ki67), HER2-enriched (ER-, PR, or HER2+), basal-like (ER-, PR-, HER2-, cytokeratin 5/6+, and/or HER1+), and normal-like (ER+ and/or PR+, HER2-, low Ki67, prognosis slightly worse than luminal A) [5-7].

Approximately $10 \%$ of $\mathrm{BC}$ cases correspond to hereditary factors with germline mutations in BRCA1, BRCA2, TP53, E-Cadherin, STK11, PTEN, ATM, and CHEK2 genes, while $90 \%$ of mammary tumors are adenocarcinomas with the presence of somatic mutations in high-penetrance genes such as PIK3CA, AKT1, SF3B1, GATA3, MLL3, CDH1, MAP3K1, NCOR1, MAP2K4, and MACF1 [5, 8-10]. All breast cancer's driver genes are fully detailed in the Cancer Genome Interpreter and the Pan-Cancer Atlas [11, 12]. Regarding the AKT subfamily, it is made up of three isoforms in mammals: AKT1, AKT2, and AKT3. AKT1 is located in the $14 \mathrm{q} 32.33$ position and has 14 exons that include a reading frame of 1443 base pairs (bp). AKT1 encodes the kinase B alpha $(\mathrm{PKB} \alpha)$ protein of 480 amino acids and 55686 Daltons. $\mathrm{PKB} \alpha$ contains an N-terminal pleckstrin homology $(\mathrm{PH})$ domain, a short $\alpha$-helical linker, a kinase domain (KD), and a regulatory motif $[13,14]$. Various cytokines, hormones, and growth factors active AKT1 by binding their cognate receptor tyrosine kinase (RTK), GPCR, or cytokine receptor and triggering activation of the PI3K kinase, which generates PIP3 $[15,16]$. AKT1 binds PIP3 through its $\mathrm{PH}$ domain, resulting in translocation of AKT1 to the membrane. The mTORrictor complex (mTORC2) phosphorylates AKT1 within the carboxy terminus at S473 and PDK1 phosphorylates AKT1 within its activation loop at T308 [16, 17]. Activated AKT1 phosphorylates a large number of downstream substrates that play a crucial role in regulating cell growth, metabolism, proliferation, apoptosis, angiogenesis, and drug responses [18-21].

The E17K rs121434592, E319G rs12881616, L357P rs11555432, P388T rs11555431, rs2494732, and rs3803304 single nucleotide polymorphisms (SNPs) have been identified in the AKT1 kinase gene [22]. The E17K variant generates a conformational change in the $\mathrm{PH}$ domain of the AKT1 protein, making it possible to join the protein and the cell membrane, causing the process of intracellular phosphorylation [23]. The E319G, L357P, and P388T variants are located in the kinase domain (KD), and the rs2494732 and rs3803304 variants are placed in intronic regions (Figure 1). Consequently, dysregulation in cell proliferation, survival, and growth drives progressive transformation of normal cells towards a malignant phenotype [18, 24-27]. Aberrant AKT signaling is the underlying defect found in several pathologies such as esophageal cancer [28], head and neck cancer [29], and non-small cell lung cancer [30].

The objective was to determine the risk of breast cancer associated with histopathological and immunohistochemical characteristics and genetic polymorphisms in a high altitude Ecuadorian mestizo population.

\section{Materials and Methods}

2.1. Study Subjects. The Bioethics Committee of our institution, conducted following the Declaration of Helsinki, approved this retrospective case-control study. It comprised a total of 276 Ecuadorian mestizo women who live 2,800 meters above sea level (masl) and were included into the analysis. Concerning the individuals with BC, 91 samples from tumor tissue embedded in paraffin with luminal A, luminal B, HER2-enriched, and basal-like subtypes were obtained from the Pathology Department at Solon Espinosa Ayala Oncologic Hospital. Affected individuals were diagnosed with BC between 2008 and 2011. Each case history conferred relevant information such as age, affected breast, surgical margins, tumor stage (T1-T4), pTNM (tumor, nodule, and metastasis) classification, histopathological and molecular classification, ER status, PR status, and HER2 status. With regard to the control group, 185 peripheral blood samples from individuals of the mestizo population with no family or personal history of cancer or smoking history were selected at random from our sample collection. Thus, the matching of cases to controls presented similar age (54.0 versus 52.3 years), age at menopause ( 47.4 versus 46.7 years), age at menarche (14.2 versus 14.6 years), age at first live birth (26.8 versus 26.2 years), mean number of live births (2.5 versus 2.5), and breast cancer in first-degree relative (3.1 versus 2.1 percent), respectively. Furthermore, all participants included in the study signed their respective informed consent.

2.2. DNA Extraction and Purification. DNA extraction and purification of control and case individuals were performed using the Wizard Genomic DNA Purification Kit (Promega, Madison, WI) and the PureLink Genomic DNA Kit (Invitrogen, Carlsbad, CA), respectively. The DNA of the healthy individuals was extracted from peripheral blood samples and presented an average concentration of $135 \mathrm{ng} / \mu \mathrm{l}$. Meanwhile, the DNA of the affected individuals, which presented an average concentration of $84 \mathrm{ng} / \mu \mathrm{l}$, was extracted from ten sections $(5 \mu \mathrm{m})$ of formalin-fixed paraffin-embedded breast tumor tissue previously cut with a microtome CUT 6062 (SLEE, Mainz, Germany). Both calculations were obtained using NanoDrop 2000 (Thermo Scientific, Waltham, MA).

2.3. Amplification and Genotyping. Genotyping was performed using DNA sequencing analysis. A final volume of $20 \mu \mathrm{l}$ was used for each PCR reaction for AKT1 SNPs. Each reaction consisted of $16.2 \mu \mathrm{l}$ of Milli-Q water, $2 \mu \mathrm{l}$ of DNA template $(10 \mathrm{ng} / \mu \mathrm{l}), 0.2 \mu \mathrm{M}$ of each deoxynucleotide triphosphate (dNTP's), $3 \mathrm{mM}$ of $\mathrm{MgCl}_{2}, 0.05 \mathrm{U}$ of Taq DNA polymerase, $2.5 \mu \mathrm{l}$ of $10 \mathrm{X}$ buffer $(500 \mathrm{mM}$ of $\mathrm{KCl}, 200 \mathrm{mM}$ of Tris- $\mathrm{HCl}, \mathrm{pH}=8.4$ ), and $0.4 \mu \mathrm{M}$ of forward (FW) and reverse (RV) primers detailed in Table 1.

The SNPs E17K rs121434592 (G>A) (198 bp), L357P rs11555432 (T>C) (142 bp), E319G rs12881616 (A>G) (186 bp), and P388T rs11555431 (C>A) (171 bp) presented in exonic regions and rs3803304 (C>G) (171 bp) and rs2494732 (C>T) (171 bp) presented in intronic regions were amplified through the polymerase chain reaction (PCR) technique. Supplementary Table 2 details the genetic variants analyzed in this study. The PCR program started with an initial denaturation stage lasting 5 minutes at $94^{\circ} \mathrm{C}$, followed by 35 cycles of 50 seconds at $94^{\circ} \mathrm{C}, 50$ seconds at different annealing temperatures 


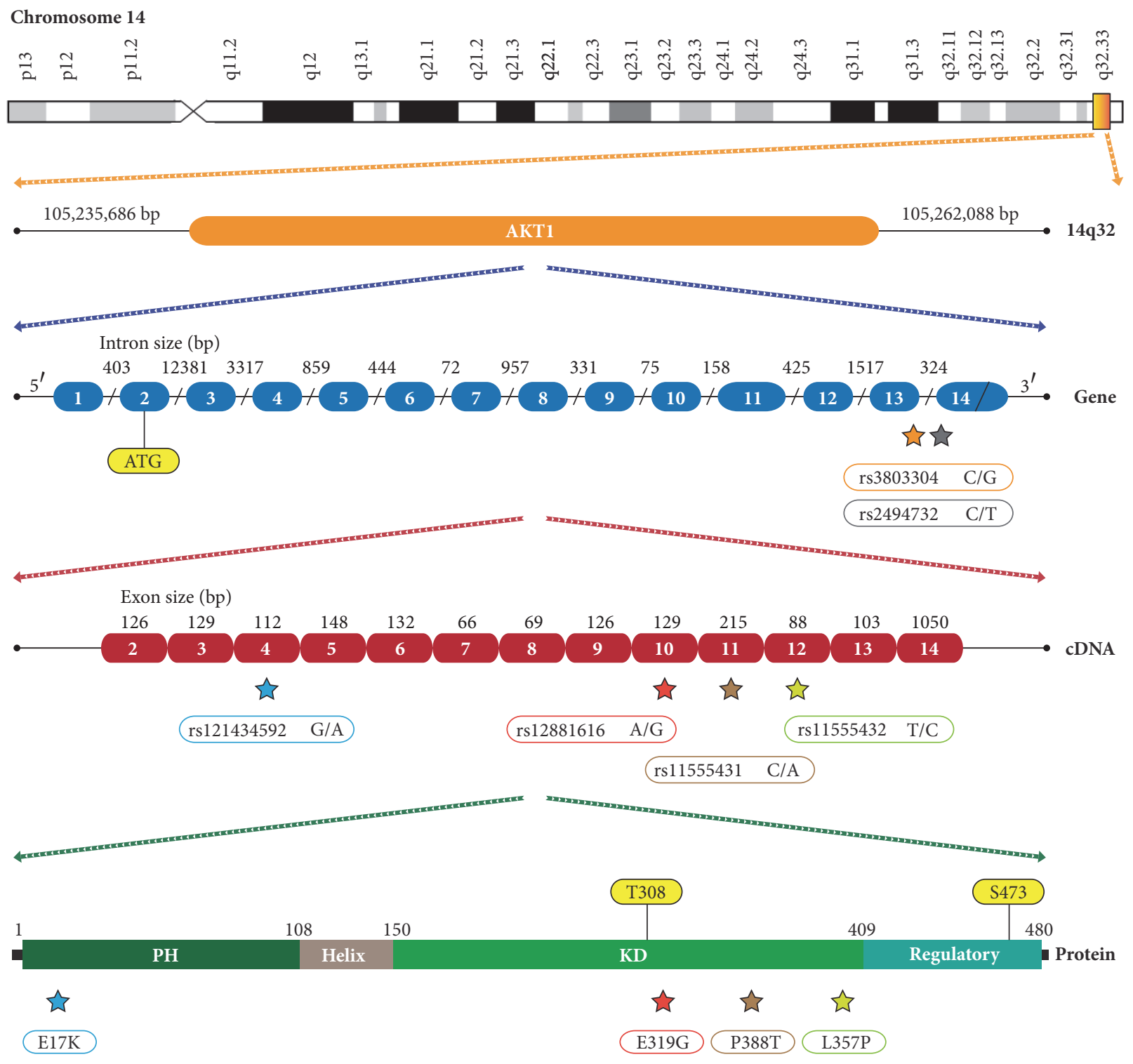

FIGURE 1: Location of the rs121434592, rs12881616, rs11555432, rs11555431, rs2494732, and rs3803304 variants in chromosome 14 in the AKT1 gene.

(Table 1), 45 seconds at $70^{\circ} \mathrm{C}$, and a final elongation for 3 minutes at $72^{\circ} \mathrm{C}$. Each run was completed using a Sure Cycler 8800 thermocycler (Agilent, Santa Clara, CA). The amplified fragment was then separated by electrophoresis in $2 \%$ agarose gels stained with ethidium bromide and was observed in an ImageQuant 300 transilluminator (General Electric, Fairfield, SC).

Genotyping was performed using DNA sequencing analysis through Genetic Analyzer 3130 (Applied Biosystems, Austin, TX). The final volume of the reaction was $12 \mu \mathrm{l}$ and contained $2.8 \mu \mathrm{l}$ of Milli-Q water, $2 \mu \mathrm{l}$ of $5 \mathrm{X}$ buffer, $1 \mu \mathrm{l}$ of primer FW (3.2 pmol), $1 \mu \mathrm{l}$ of BigDye Terminator v3.1 sequencing standard (Applied Biosystems, Austin, TX), and $3 \mu \mathrm{l}$ of PCR product ( 3 to $10 \mathrm{ng}$ ). Once the product was amplified, it was then purified using Agencourt CleanSEQ (Beckman Coulter, Miami, FL). The amplification program consisted of 3 minutes at $96^{\circ} \mathrm{C}$, followed by 30 cycles of 10 seconds at $96^{\circ} \mathrm{C}, 5$ seconds at $50^{\circ} \mathrm{C}$, and 4 minutes at $60^{\circ} \mathrm{C}$. Finally, sequence analysis was performed using Sequencing Analysis Software 5.3.1 (Applied Biosystems, Austin, TX), and the alignment with sequences from GenBank (AKT1 NC_000014.9) was performed using Seq-Scape Software v2.6 (Applied Biosystems, Austin, TX) [7].

2.4. Statistical Analysis. The information from the clinical records of the patients was collected and stored in a database. Allelic and genotypic frequencies of the AKT1 SNPs were calculated; also Hardy-Weinberg equilibrium was determined by using a tool available on the Internet (http://www.oege.org/software/hwe-mr-calc.shtml) [31]. With the use of IBM SPSS Statistics 22 software (SPSS Inc., Chicago, IL), chi-square $\left(\chi^{2}\right)$, and odds ratio (OR) (with a 
TABLE 1: Primer sequences, annealing temperatures, and genetic variations.

\begin{tabular}{|c|c|c|c|c|}
\hline Polymorphisms & Primer sequences & Annealing temperatures & Location & Fragment (bp) \\
\hline \multirow{2}{*}{$\begin{array}{l}\text { rs121434592 } \\
\text { E17K }\end{array}$} & FW 5’- GGC CAA GGG GAT ACT TAC GC -3’ & \multirow{2}{*}{60} & \multirow{2}{*}{ Exon 4} & \multirow{2}{*}{198} \\
\hline & RV 5'- AGG GTC TGA CGG GTA GAG TG -3' & & & \\
\hline \multirow{2}{*}{$\begin{array}{l}\text { rs11555432 } \\
\text { L357P }\end{array}$} & FW 5'- CCT TCT TGA GCA GCC CTG AA -3' & \multirow{2}{*}{56.5} & \multirow{2}{*}{ Exon 12} & \multirow{2}{*}{142} \\
\hline & RV 5’- TAC GAG ATG ATG TGC GGT CG -3’ & & & \\
\hline \multirow{2}{*}{$\begin{array}{l}\text { rs12881616 } \\
\text { E319G }\end{array}$} & FW 5'- CAG AGA GGA CAC AGC ATT GCG -3' & \multirow{2}{*}{60.5} & \multirow{2}{*}{ Exon 10} & \multirow{2}{*}{186} \\
\hline & RV 5’- ACA AGG ACG GGC ACA TTA AGA -3' & & & \\
\hline \multirow{2}{*}{$\begin{array}{l}\text { rs11555431 } \\
\text { P388T }\end{array}$} & FW 5'- CAA GGA CAT CAA GCT TTG GCT -3’ & \multirow{2}{*}{61} & \multirow{2}{*}{ Exon 11} & \multirow{2}{*}{171} \\
\hline & RV 5’- AAG TCC TTG CTT TCA GGG CT -3’ & & & \\
\hline \multirow{2}{*}{ rs3803304 } & FW 5'- CAA GGA CAT CAA GCT TTG GCT -3' & \multirow{2}{*}{61} & \multirow{2}{*}{ Intron 13} & \multirow{2}{*}{171} \\
\hline & RV 5’- AAG TCC TTG CTT TCA GGG CT -3’ & & & \\
\hline \multirow{2}{*}{ rs2494732 } & FW 5’- CAA GGA CAT CAA GCT TTG GCT -3’ & \multirow{2}{*}{61} & \multirow{2}{*}{ Intron 13} & \multirow{2}{*}{171} \\
\hline & RV 5’- AAG TCC TTG CTT TCA GGG CT -3’ & & & \\
\hline
\end{tabular}

bp, base pairs.

95\% confidence interval $[\mathrm{CI}]$ and $2 \times 2$ contingency table), tests were applied to determine the association between the risk of developing BC, the SNPs, histopathological characteristics, and immunohistochemical characteristics. $P<0.05$ was considered statistically significant. Consequently, the false discovery rate (FDR) Benjamini/Hochberg correction was performed in order to obtain $Q$ values.

\section{Results}

The distribution of baseline characteristics in all patients with BC is shown in Table 2 and is fully detailed in Supplementary Table 1. Regarding age of diagnosis, $72.7 \%$ of luminal B individuals, $58.5 \%$ of luminal A, $56.3 \%$ of basal-like, $36.4 \%$ of HER2-enriched, and 57.1\% of all cases presented were 50 years old or older. The right breast was affected in $57.1 \%$ of all cases, from which $72.6 \%$ presented luminal B, 58.5\% luminal A, 50\% basal-like, and 45.5\% HER2-enriched. Regarding $\mathrm{T}$ stage, 93.8\% of basal-like individuals, $77 \%$ of luminal A, $72.7 \%$ of HER2-enriched, $54.5 \%$ of luminal B, and $76.9 \%$ of all cases presented T1-T2 stage. Positive LN status was presented in $51.6 \%$ of all cases. Negative ER status was presented in $35.2 \%$ of all cases, from which $100 \%$ of basal-like individuals, $100 \%$ of HER2-enriched, 9.1\% of luminal B, and 7.5\% of luminal A did not present this receptor $(P \leq 0.001 ; Q \leq 0.05)$. Regarding PR status, a total of $39.6 \%$ presented a negative PR status, of which $100 \%$ was basal-like, $90.9 \%$ was HER2-enriched and luminal $\mathrm{B}$, and $79.2 \%$ was luminal $\mathrm{A}(P \leq 0.001 ; Q \leq 0.05)$. Overall, 70.3\% presented negative HER2-enriched status, of which $100 \%$ was basal-like, $79.2 \%$ was luminal A, and $54.5 \%$ was luminal B $(P \leq 0.001 ; Q \leq 0.05)$. Finally, $67 \%$ of all cases presented positive and $33 \%$ presented negative surgical margins.

Frequency of mutations in the AKT1 gene in breast cancer subtypes is detailed in Table 2 and genotype distribution and allele frequencies of AKT1 mutations in cases and controls are detailed in Table 3. The E17K AA homozygous genotype had a frequency of 0.02 in cases and 0.00 in control and was present in $2 / 91$ affected individuals $(2.2 \%)$ and $6.25 \%$ of basal-like type $(P>0.05 ; Q>0.05)$. The E319G GG, L357P CC, and $\mathrm{P} 388 \mathrm{~T}$ AA genotypes had a frequency of 0.00 in cases and controls and were present in $0 / 91$ affected individuals $(0 \%)$. The rs2494732 TT mutant genotype had a frequency of 0.14 in cases and 0.22 in controls and was present in 13/91 affected individuals (14.29\%) and 36.4\% of HER individuals $(P>0.05$; $Q>0.05)$. The rs3803304 mutant homozygous genotype had a frequency of 0.08 in cases and 0.02 in controls and was present in 7/91 affected individuals (7.7\%) and $18.2 \%$ of HER individuals $(P>0.05 ; Q>0.05)$, whereas the rs3803304 CG heterozygous genotype was significantly different among the four subtypes $(P \leq 0.05 ; Q \leq 0.05)$, where luminal $\mathrm{B}$ had the highest percentage $(63.6 \%)$. Finally, the alleles of the rs2494732 and rs3803304 SNPs presented Hardy-Weinberg equilibrium.

The association between rs2494732 and rs3803304 polymorphisms and the risk of developing BC is detailed in Table 4. Regarding variant rs2494732, the CT genotype presented an odds ratio (OR) of 0.6 (95\% CI $=0.3-1.0 ; P>$ $0.05 ; Q>0.05)$; the TT genotype presented an OR of $0.4(95 \%$ $\mathrm{CI}=0.2-0.9 ; P \leq 0.05 ; Q>0.05)$; and the combination of CT+TT presented an OR of 0.5 (95\% CI $=0.3-0.9 ; P \leq 0.05$; $Q>0.05)$. Regarding the rs3803304 intronic variant, the $C G$ genotype presented an OR of 1.1 (95\% CI $=0.6-1.9 ; P>0.05$; $Q>0.05)$; the GG genotype presented an OR of $5.2(95 \%$ $\mathrm{CI}=1.3-20.9 ; P \leq 0.05 ; Q>0.05)$; and the combination of CG+GG presented an OR of $1.3(95 \% \mathrm{CI}=0.8-2.2 ; P>0.05$; $Q>0.05)$. The $\mathrm{OR}$ in the remaining polymorphisms was not calculated due to low and nonexisting frequency in the study population.

The association between the rs3803304 and rs2494732 polymorphisms and the histopathological and immunohistochemical characteristics is detailed in Table 5. Regarding the affected breast, tumor stage, LN status, ER status, PR status, HER2 status, and surgical margins, no statistically significant differences $(P>0.05 ; Q>0.05)$ were found in relation to the genetic polymorphisms. Additionally, data of control individuals is fully detailed in Supplementary Table 3 . 
TABLE 2: Distribution ( $n, \%)$ of baseline characteristics (at diagnosis) and frequency of AKT1 mutations in patients with all breast cancer subtypes.

\begin{tabular}{|c|c|c|c|c|c|c|c|c|c|c|c|c|}
\hline & \multicolumn{2}{|c|}{ Luminal A } & \multicolumn{2}{|c|}{ Luminal B } & \multicolumn{2}{|c|}{ HER2-enriched } & \multicolumn{2}{|c|}{ Basal-like } & \multicolumn{2}{|c|}{ All } & \multirow{2}{*}{$P$ value } & \multirow{2}{*}{$\begin{array}{c}\text { FDR } \\
Q \text { value }\end{array}$} \\
\hline & $n$ & $\%$ & $n$ & $\%$ & $n$ & $\%$ & $n$ & $\%$ & $n$ & $\%$ & & \\
\hline \multicolumn{13}{|c|}{ Age at diagnosis } \\
\hline$<35$ & 1 & 1.9 & 0 & 0.0 & 1 & 9.1 & 0 & 0.0 & 2 & 2.2 & \multicolumn{2}{|c|}{ Reference } \\
\hline $35-49$ & 21 & 39.6 & 3 & 27.3 & 6 & 54.5 & 7 & 43.75 & 37 & 40.7 & $P>0.05$ & $Q>0.05$ \\
\hline$\geq 50$ & 31 & 58.5 & 8 & 72.7 & 4 & 36.4 & 9 & 56.25 & 52 & 57.1 & $P>0.05$ & $Q>0.05$ \\
\hline \multicolumn{13}{|c|}{ Affected breast } \\
\hline Right & 31 & 58.5 & 8 & 72.7 & 5 & 45.5 & 8 & 50.0 & 52 & 57.1 & \multirow[t]{2}{*}{$P>0.05$} & \multirow[t]{2}{*}{$Q>0.05$} \\
\hline Left & 22 & 41.5 & 3 & 27.3 & 6 & 54.5 & 8 & 50.0 & 39 & 42.9 & & \\
\hline \multicolumn{13}{|c|}{ T stage } \\
\hline T1-T2 & 41 & 77.36 & 6 & 54.5 & 8 & 72.7 & 15 & 93.75 & 70 & 76.92 & \multicolumn{2}{|c|}{ Reference } \\
\hline T3-T4 & 9 & 16.98 & 5 & 45.5 & 3 & 27.3 & 1 & 6.25 & 18 & 19.78 & $P>0.05$ & $Q>0.05$ \\
\hline T0, X & 3 & 5.66 & 0 & 0.0 & 0 & 0.0 & 0 & 0.00 & 3 & 3.30 & $P>0.05$ & $Q>0.05$ \\
\hline \multicolumn{13}{|c|}{ LN status } \\
\hline+ & 28 & 52.8 & 3 & 27.3 & 9 & 81.8 & 7 & 43.75 & 47 & 51.6 & \multirow[t]{2}{*}{$P>0.05$} & \multirow[t]{2}{*}{$Q>0.05$} \\
\hline- & 25 & 47.2 & 8 & 72.7 & 2 & 18.2 & 9 & 56.25 & 44 & 48.4 & & \\
\hline \multicolumn{13}{|c|}{ ER status } \\
\hline+ & 49 & 92.5 & 10 & 90.9 & 0 & 0.0 & 0 & 0.0 & 59 & 64.8 & \multirow[t]{2}{*}{$P \leq 0.001$} & $Q \leq 0.05$ \\
\hline- & 4 & 7.5 & 1 & 9.1 & 11 & 100 & 16 & 100 & 32 & 35.2 & & \\
\hline PR stat & & & & & & & & & & & & \\
\hline+ & 53 & 100 & 1 & 9.1 & 1 & 9.1 & 0 & 0.0 & 55 & 60.4 & $P \leq 0.001$ & $Q \leq 0.05$ \\
\hline- & 0 & 0.0 & 10 & 90.9 & 10 & 90.9 & 16 & 100 & 36 & 39.6 & & \\
\hline HER2 & tus & & & & & & & & & & & \\
\hline+ & 11 & 20.8 & 5 & 45.5 & 11 & 100 & 0 & 0.0 & 27 & 29.7 & $P \leq 0.001$ & $Q \leq 0.05$ \\
\hline- & 42 & 79.2 & 6 & 54.5 & 0 & 0.0 & 16 & 100 & 64 & 70.3 & & \\
\hline Surgica & marg & & & & & & & & & & & \\
\hline+ & 33 & 62.3 & 8 & 72.7 & 7 & 63.6 & 13 & 81.25 & 61 & 67.0 & $P>0.05$ & $Q>0.05$ \\
\hline- & 20 & 37.7 & 3 & 27.3 & 4 & 36.4 & 3 & 18.75 & 30 & 33.0 & & \\
\hline rs12143 & $92 \mathrm{E}$ & & & & & & & & & & & \\
\hline GG & 52 & 98.1 & 11 & 100 & 11 & 100 & 15 & 93.75 & 89 & 97.8 & Reference & \\
\hline GA & 0 & 0.0 & 0 & 0.0 & 0 & 0.0 & 0 & 0.0 & 0 & 0.0 & - & - \\
\hline $\mathrm{AA}$ & 1 & 1.9 & 0 & 0.0 & 0 & 0.0 & 1 & 6.25 & 2 & 2.2 & $P>0.05$ & $Q>0.05$ \\
\hline rs12881 & $6 \mathrm{E} 31$ & & & & & & & & & & & \\
\hline $\mathrm{AA}$ & 53 & 100 & 11 & 100 & 11 & 100 & 16 & 100 & 91 & 100 & & \\
\hline $\mathrm{AG}$ & 0 & 0.0 & 0 & 0.0 & 0 & 0.0 & 0.0 & 0.0 & 0 & 0.0 & - & - \\
\hline GG & 0 & 0.0 & 0 & 0.0 & 0 & 0.0 & 0.0 & 0.0 & 0 & 0.0 & - & - \\
\hline rs11555 & $2 \mathrm{~L} 3$ & & & & & & & & & & & \\
\hline $\mathrm{TT}$ & 53 & 100 & 11 & 100 & 11 & 100 & 16 & 100 & 91 & 100 & & \\
\hline TC & 0 & 0.0 & 0 & 0.0 & 0 & 0.0 & 0.0 & 0.0 & 0 & 0.0 & - & - \\
\hline $\mathrm{CC}$ & 0 & 0.0 & 0 & 0.0 & 0 & 0.0 & 0.0 & 0.0 & 0 & 0.0 & - & - \\
\hline rs11555 & $1 \mathrm{P} 38$ & & & & & & & & & & & \\
\hline $\mathrm{CC}$ & 53 & 100 & 11 & 100 & 11 & 100 & 16 & 100 & 91 & 100 & & \\
\hline $\mathrm{CA}$ & 0 & 0.0 & 0 & 0.0 & 0 & 0.0 & 0.0 & 0.0 & 0 & 0.0 & - & - \\
\hline $\mathrm{AA}$ & 0 & 0.0 & 0 & 0.0 & 0 & 0.0 & 0.0 & 0.0 & 0 & 0.0 & - & - \\
\hline rs2494 & & & & & & & & & & & & \\
\hline $\mathrm{CC}$ & 24 & 45.3 & 5 & 45.45 & 6 & 54.5 & 6 & 37.5 & 41 & 45.05 & & \\
\hline $\mathrm{CT}$ & 24 & 45.3 & 4 & 36.36 & 1 & 9.1 & 8 & 50.0 & 37 & 40.66 & $P>0.05$ & $Q>0.05$ \\
\hline TT & 5 & 9.4 & 2 & 18.18 & 4 & 36.4 & 2 & 12.5 & 13 & 14.29 & $P>0.05$ & $Q>0.05$ \\
\hline
\end{tabular}


TABLE 2: Continued.

\begin{tabular}{ccccccccccccc}
\hline & \multicolumn{2}{c}{ Luminal A } & \multicolumn{2}{c}{ Luminal B } & \multicolumn{2}{c}{ HER2-enriched } & \multicolumn{2}{c}{ Basal-like } & All & FDR \\
& $n$ & $\%$ & $n$ & $\%$ & $n$ & $\%$ & $n$ & $\%$ & $n$ & $\%$ & \\
\hline rs3803304 & & & & & & & & & & \\
\hline CC & 31 & 58.5 & 4 & 36.4 & 4 & 36.4 & 15 & 93.8 & 54 & 59.3 & Reference \\
\hline CG & 18 & 34.0 & 7 & 63.6 & 5 & 45.5 & 0 & 0.0 & 30 & 33.0 & $P \leq 0.05$ & $Q \leq 0.05$ \\
\hline GG & 4 & 7.5 & 0 & 0.0 & 2 & 18.2 & 1 & 6.3 & 7 & 7.7 & $P>0.05$ & $Q>0.05$ \\
\hline
\end{tabular}

LN, lymph node; ER, estrogen receptor; PR, progesterone receptor; HER, human epidermal growth factor receptor; FDR, false discovery rate.

TABLE 3: Genotype distribution and allele frequency of AKT1 mutations in cases and controls.

\begin{tabular}{|c|c|c|c|c|c|c|c|}
\hline \multirow{2}{*}{ Mutations } & \multirow{2}{*}{ Genotypes } & \multicolumn{3}{|c|}{ Genotypic frequency } & \multicolumn{3}{|c|}{ Allele frequency } \\
\hline & & Cases & Controls & All & Cases & Controls & All \\
\hline \multirow{3}{*}{$\begin{array}{l}\text { rs121434592 } \\
\text { E17K }\end{array}$} & GG & 0.98 & 1.00 & 0.99 & 0.98 & 1.00 & 0.99 \\
\hline & GA & 0.00 & 0.00 & 0.00 & & & \\
\hline & $\mathrm{AA}$ & 0.02 & 0.00 & 0.01 & 0.02 & 0.00 & 0.01 \\
\hline \multirow{3}{*}{$\begin{array}{l}\text { rs12881616 } \\
\text { E319G }\end{array}$} & AA & 1.00 & 1.00 & 1.00 & 1.00 & 1.00 & 1.00 \\
\hline & AG & 0.00 & 0.00 & 0.00 & & & \\
\hline & GG & 0.00 & 0.00 & 0.00 & 0.00 & 0.00 & 0.00 \\
\hline \multirow{3}{*}{$\begin{array}{l}\text { rs11555432 } \\
\text { L357P }\end{array}$} & $\mathrm{TT}$ & 1.00 & 1.00 & 1.00 & 1.00 & 1.00 & 1.00 \\
\hline & TC & 0.00 & 0.00 & 0.00 & & & \\
\hline & $\mathrm{CC}$ & 0.00 & 0.00 & 0.00 & 0.00 & 0.00 & 0.00 \\
\hline \multirow{3}{*}{$\begin{array}{l}\text { rs11555431 } \\
\text { P388T }\end{array}$} & CC & 1.00 & 1.00 & 1.00 & 1.00 & 1.00 & $\overline{1.00}$ \\
\hline & $\mathrm{CA}$ & 0.00 & 0.00 & 0.00 & & & \\
\hline & AA & 0.00 & 0.00 & 0.00 & 0.00 & 0.00 & 0.00 \\
\hline \multirow{3}{*}{ rs 2494732} & CC & 0.45 & 0.30 & 0.34 & 0.65 & 0.54 & 0.57 \\
\hline & CT & 0.41 & 0.48 & 0.46 & & & \\
\hline & $\mathrm{TT}$ & 0.14 & 0.22 & 0.20 & 0.35 & 0.46 & 0.43 \\
\hline \multirow{3}{*}{ rs3803304 } & $\mathrm{CC}$ & 0.59 & 0.65 & 0.63 & 0.76 & 0.82 & 0.80 \\
\hline & CG & 0.33 & 0.33 & 0.33 & & & \\
\hline & GG & 0.08 & 0.02 & 0.04 & 0.24 & 0.18 & 0.20 \\
\hline
\end{tabular}

\section{Discussion}

During the last decade, breast cancer genome-wide association studies (GWAS) have identified $\sim 80$ loci with small-tomoderate effects on OR ranging from 1.05 to 1.53 [10, 32-34]. Studying SNPs is crucial to fully understand breast cancer biology, as well as for the development of novel therapeutics for cancer treatment and for providing methods for prevention and early diagnosis [35]. The most studied populations have been Asian, European, and African. However, Latin American populations have been poorly studied, making genetic characterization essential to better understand the development of $\mathrm{BC}[7,36]$.

Mounting evidence exists that activation of AKT proteins is important in cancer development [14]. Hyperactivation of the AKT pathway has been detected in up to $50 \%$ of all human tumors and is closely associated with chemoresistance [37]. Therefore, AKT has been an attractive target for anticancer drug discovery [38]. In particular, genetic alterations of the AKT genes have been demonstrated in many human tumors, including breast, colorectal, and ovarian cancers [39]. Concerning BC, the activating mutations of AKT1 gene have not been widely reported, the first being a study conducted in a female Latin American mestizo population from a high altitude $(2,800$ masl). It is noteworthy that this retrospective research presented a limited number of cases. However, it gives us relevant information about BC risk and its association with genotype polymorphisms of the AKT1 gene.

The E17K (rs121434592) point mutation in the pleckstrin homology domain of the AKT1 gene is the major point mutation that has been reported in the literature. In 2007, Carpten et al. evaluated the complete coding regions of AKT family members for mutations in genomic DNA from clinical tumour specimens representing breast $(n=61)$, colorectal $(n=51)$, and ovarian $(n=50)$ cancers [39]. Analysis of these samples revealed a unique mutation in the $\mathrm{PH}$ domain of AKT1 which results in a lysine substitution for glutamic acid at amino acid 17. E17K was identified in 5 of $51(8 \%)$ breast, 3 of $51(6 \%)$ colorectal, and 1 of $50(2 \%)$ ovarian cancers. Although the sample size was insufficient to document statistical significance, the lack of coincidence of these mutations indicates that the AKT1 mutation (E17K) is sufficient for pathological activation of the PI3K/AKT 
TABLE 4: Association between rs2494732 and rs3803304 polymorphisms and breast cancer risk among cases and controls.

\begin{tabular}{|c|c|c|c|c|c|c|c|}
\hline Mutations & Genotypes & $\begin{array}{c}\text { Cases }(n=91) \\
n(\%)\end{array}$ & $\begin{array}{c}\text { Controls }(n= \\
185), \\
n(\%)\end{array}$ & OR & $95 \% \mathrm{CI}$ & $P$ value & $\begin{array}{c}\text { FDR } \\
Q \text { value }\end{array}$ \\
\hline \multirow{4}{*}{ rs2494732 } & $\mathrm{CC}^{\mathrm{a}}$ & $41(45)$ & $56(30)$ & 1.0 & & Reference & \\
\hline & $\mathrm{CT}$ & $37(41)$ & $89(48)$ & 0.6 & $0.3-1.0$ & $P>0.05$ & $Q>0.05$ \\
\hline & TT & $13(14)$ & $40(22)$ & 0.4 & $0.2-0.9$ & $P \leq 0.05$ & $Q>0.05$ \\
\hline & $\mathrm{CT}+\mathrm{TT}$ & $50(55)$ & $129(70)$ & 0.5 & $0.3-0.9$ & $P \leq 0.05$ & $Q>0.05$ \\
\hline \multirow{4}{*}{ rs3803304 } & $\mathrm{CC}^{\mathrm{a}}$ & $54(59)$ & $121(65)$ & 1.0 & & Reference & \\
\hline & CG & $30(33)$ & $61(33)$ & 1.1 & $0.6-1.9$ & $P>0.05$ & $Q>0.05$ \\
\hline & GG & $7(8)$ & $3(2)$ & 5.2 & $1.3-20.9$ & $P \leq 0.05$ & $Q>0.05$ \\
\hline & $\mathrm{CG}+\mathrm{GG}$ & $37(41)$ & $64(35)$ & 1.3 & $0.8-2.2$ & $P>0.05$ & $Q>0.05$ \\
\hline
\end{tabular}

OR, odds ratio; CI, confidence interval; FDR, false discovery rate

${ }^{\mathrm{a}}$ References.

pathway [40]. In 2008, Stemke-Hale et al. published that E17K mutation was detected in only 6 of 418 breast cancers (1.4\%), where all of them presented ER+ and PR+ [41]. In that year, Kim et al. identified the E17K mutation in 4 of 93 (4.3\%) invasive ductal carcinomas [42]. En 2014, Shanti et al. used different genomic algorithms (SIFT, Polyphen 2.0, I-Mutant 2.0, and SNPs\&GO) for prioritization of highrisk missense mutations in coding regions of $\mathrm{AKT1}$ gene. They revealed that mutations such as E17S, E319G, L357P, and P388T were probably damaging and these mutations should be considered alongside E17K in the therapeutic development of AKT inhibitors to treat human cancer [22]. In the high altitude Ecuadorian mestizo population, the E17K mutation was found in 2 of 91 individuals $(2.2 \%)$, where one of them was luminal $\mathrm{A}$ and the other one was basal-like (Table 2). In spite of the low percentage found in our population, it is known that the E17K (rs121434592) substitution decreases the sensitivity to an allosteric kinase inhibitor, so this mutation may have important clinical utility for AKT drug development [43].

According to the analysis of prioritization of Shanti et al., the E319G (rs12881616), L357P (rs11555432), and P388T (rs11555431) exonic variants are high-risk missense mutations of the AKT1 gene [22]. Nevertheless, these variants are $100 \%$ present in their normal homozygous state in this study due to a small sample size of the high altitude Ecuadorian mestizo population. On the other hand, the analysis of the rs 2494732 and rs3803304 intronic variants was carried out. As for the rs 2494732 variant, the CT genotype is found in $40.66 \%$ of the affected population with a higher percentage in the basal-like subtype (50\%) and luminal A subtype (45.3\%), whereas the TT genotype is found in $14.29 \%$ of the affected population with a higher percentage in the luminal A subtype (9.4\%) and HER2-enriched subtype (36.4\%). The OR statistical test determined that the rs2494732 variant did not present risk with the development of breast cancer in the CT heterozygous genotypes $(\mathrm{OR}=0.6,95 \% \mathrm{CI}=0.3-1.0 ; P>0.05 ; Q>$ 0.05 ) or TT mutant homozygous genotypes ( $\mathrm{OR}=0.4,95 \%$ $\mathrm{CI}=0.2-0.9 ; P \leq 0.05 ; Q>0.05)$, just as found in the Chinese Han population with basocellular skin cancer (OR $=1.00,95 \% \mathrm{CI}=0.5-2.2 ; P>0.05)[41]$. As a matter of fact, in this population, the $\mathrm{T}$ mutant allele presented a higher allele frequency (0.46) in controls than in cases (0.35), and the $\mathrm{C}$ normal allele had a higher allele frequency in cases (0.65) than in controls (0.54). These results prove that the presence of mutations in the rs 2494732 variant is related to a protective factor in the development of breast cancer and is associated with better general survival with a hazard ratio (HR) of 0.59 (95\% CI $=0.40-0.86 ; P \leq 0.05)$ and progression-free survival with a $\mathrm{HR}$ of $0.74(95 \% \mathrm{CI}=0.53$ $1.03 ; P>0.05)$ in a Korean population with non-small cell lung cancer [30]. Concerning the rs3803304 variant, the CG genotype is found in $33.0 \%$ of the affected population with a higher percentage in the luminal B subtype (63.6\%) and HER subtype (45.5\%), whereas the GG genotype is found in $7.7 \%$ of the affected population with higher percentage in the HER2-enriched subtype (18.2\%) and luminal A subtype (7.5\%). The OR statistical test determined that the rs3803304 variant presented a possible risk with the development of breast cancer in individuals with the GG mutant homozygous genotype $(\mathrm{OR}=5.2,95 \% \mathrm{CI}=1.3-20.9 ; P \leq 0.05 ; Q>0.05)$. In this mestizo population, the $\mathrm{C}$ normal allele presented a higher allele frequency in controls (0.82) than in cases (0.76), and the $\mathrm{G}$ mutant allele had a higher allele frequency in cases (0.24) than in controls (0.18). There is a statistically significant difference between the rs3803304 CG heterozygous genotype and the four subtypes $(P \leq 0.05 ; Q \leq 0.05)$, where the luminal B subtype was present in $63.6 \%$. Nevertheless, it has been observed that US individuals with esophageal cancer and the rs3803304 CG genotype presented a better response to treatments with chemoradiotherapy ( $\mathrm{OR}=0.5,95 \% \mathrm{CI}$ $=0.25-0.99 ; P \leq 0.05$ ) [28]. The results suggest that the rs3803304 variant is capable of regulating DNA transcription mechanisms and, therefore, it is capable of causing risk in the development of breast cancer in the Ecuadorian mestizo population living at high altitudes.

Regarding the rs3803304 variant that presented risk associated with the development of breast cancer, the $\mathrm{CG}+\mathrm{GG}$ combined genotypes were present in $11.4 \%$ of tumor stage T3-T4, in $20.9 \%$ of negative LN status, in $12.1 \%$ of negative ER status, in $14.3 \%$ of negative PR status, and in $24.2 \%$ of negative HER2 status. However, there was no statistically 
TABLE 5: Association of genotypes with histopathological and immunohistochemical characteristics.

\begin{tabular}{|c|c|c|c|c|}
\hline \multirow{2}{*}{ Variables } & \multicolumn{2}{|c|}{ rs3803304 } & \multicolumn{2}{|c|}{ rs2494732 } \\
\hline & $\mathrm{CC}$ & $\mathrm{CG}+\mathrm{GG}$ & $\mathrm{CC}$ & $\mathrm{CT}+\mathrm{TT}$ \\
\hline \multicolumn{5}{|c|}{ Affected breast } \\
\hline Right & $28(30.8)$ & $24(26.4)$ & $24(26.4)$ & $28(30.8)$ \\
\hline Left & $26(28.6)$ & $13(14.3)$ & $17(18.7)$ & $22(24.2)$ \\
\hline OR $(95 \%$ CI $)$ & \multicolumn{2}{|c|}{$0.6(0.2-1.4)$} & \multicolumn{2}{|c|}{$1.1(0.5-3.6)$} \\
\hline$P$ value & \multicolumn{2}{|c|}{$P>0.05, Q>0.05$} & \multicolumn{2}{|c|}{$P>0.05, Q>0.05$} \\
\hline \multicolumn{5}{|l|}{ Tumor stage $^{\text {a }}$} \\
\hline T1-T2 & $43(48.9)$ & $27(30.7)$ & $32(36.4)$ & $38(43.2)$ \\
\hline T3-T4 & $8(9.1)$ & $10(11.4)$ & $7(7.9)$ & $11(12.5)$ \\
\hline OR $(95 \%$ CI $)$ & \multicolumn{2}{|c|}{$1.9(0.7-5.7)$} & \multicolumn{2}{|c|}{$1.3(0.5-3.8)$} \\
\hline$P$ value & \multicolumn{2}{|c|}{$P>0.05, Q>0.05$} & \multicolumn{2}{|c|}{$P>0.05, Q>0.05$} \\
\hline \multicolumn{5}{|l|}{ LN status } \\
\hline+ & $29(31.9)$ & $18(19.8)$ & $22(24.1)$ & $25(27.5)$ \\
\hline- & $25(27.5)$ & $19(20.9)$ & $19(20.9)$ & $25(27.5)$ \\
\hline OR $(95 \% \mathrm{CI})$ & \multicolumn{2}{|c|}{$1.2(0.5-2.8)$} & \multicolumn{2}{|c|}{$1.2(0.5-2.6)$} \\
\hline$P$ value & \multicolumn{2}{|c|}{$P>0.05, Q>0.05$} & \multicolumn{2}{|c|}{$P>0.05, Q>0.05$} \\
\hline \multicolumn{5}{|l|}{ ER status } \\
\hline+ & $33(36.3)$ & $26(28.6)$ & $26(28.6)$ & $33(36.3)$ \\
\hline- & $21(23.1)$ & $11(12.1)$ & $15(16.5)$ & $17(18.7)$ \\
\hline OR $(95 \%$ CI $)$ & \multicolumn{2}{|c|}{$0.7(0.3-1.6)$} & \multicolumn{2}{|c|}{$0.9(0.4-2.1)$} \\
\hline$P$ value & \multicolumn{2}{|c|}{$P>0.05, Q>0.05$} & \multicolumn{2}{|c|}{$P>0.05, Q>0.05$} \\
\hline \multicolumn{5}{|l|}{ PR status } \\
\hline+ & $31(34.1)$ & $24(26.4)$ & $25(27.5)$ & $30(33.0)$ \\
\hline- & $23(25.3)$ & $13(14.3)$ & $16(17.6)$ & $20(22.0)$ \\
\hline OR $(95 \% \mathrm{CI})$ & \multicolumn{2}{|c|}{$0.7(0.3-1.7)$} & \multicolumn{2}{|c|}{$1.0(0.4-2.4)$} \\
\hline$P$ value & \multicolumn{2}{|c|}{$P>0.05, Q>0.05$} & \multicolumn{2}{|c|}{$P>0.05, Q>0.05$} \\
\hline HER2 status & & & & \\
\hline+ & $12(13.2)$ & $15(16.5)$ & $11(8.8)$ & $16(20.9)$ \\
\hline- & $42(46.2)$ & $22(24.2)$ & $30(25.3)$ & $34(45.1)$ \\
\hline OR $(95 \% \mathrm{CI})$ & & & & \\
\hline$P$ value & & & & \\
\hline Surgical marg & & & & \\
\hline+ & $33(36.3)$ & $28(30.8)$ & $25(27.5)$ & $36(39.6)$ \\
\hline- & $21(23.1)$ & $9(9.9)$ & $16(17.6)$ & $14(15.4)$ \\
\hline OR $(95 \% \mathrm{CI})$ & & & & \\
\hline$P$ value & & & & \\
\hline
\end{tabular}

LN, lymph node; PR, progesterone receptor; ER, estrogen receptor; HER, human epidermal growth factor receptor.

${ }^{a}$ Analyses of 88 individuals.

significant association between these combined genotypes and the histopathological characteristics $(P>0.05 ; Q \leq 0.05)$.

According to our results, the noncoding region rs3803304 variant may act as a predictive biomarker in the risk of developing breast cancer in the high altitude Ecuadorian mestizo population. Nevertheless, sample size should be increased in future analysis to enrich statistical tests. In conclusion, this study as well as our previous genetic studies on MTHFR in breast and prostate cancer [7, 44, 45], EGFR in lung cancer [46], and GPX-1 in bladder cancer [47] is an important contribution in order to integrate pharmacogenetics in clinical practice in Ecuador and Latin America [48, 49].

\section{Data Availability}

All data generated or analyzed during this study are included in this published article and its supplementary information files. Supplementary table 1 and table 3 detail clinical data of cases and controls, respectively. Clinical data is structured by genotype information, estrogen status, progesterone status, HER2/neu status, molecular subtypes, age at diagnosis, affected breast, surgical margins, lymph node status, and tumor stage. Supplementary table 2 details information about polymorphisms, nucleotide change, and amino acid change. All these data support the conclusions of the study. 


\section{Conflicts of Interest}

The authors declare that they have no conflicts of interest.

\section{Supplementary Materials}

Supplementary Table 1: genotypes and clinical data of cases. Supplementary Table 2: genetic variants. Supplementary Table 3: genotypes and clinical data of controls. (Supplementary Materials)

\section{References}

[1] S. Tuzlali, Pathology of Breast Cancer. In: Breast Disease: Diagnosis and Pathology, 2015.

[2] Uk CR, "Worldwide cancer statistics. Cancer Res," Cancer Res, 2014.

[3] A. Jemal, F. Bray, M. M. Center, J. Ferlay, E. Ward, and D. Forman, "Global cancer statistics," CA: A Cancer Journal for Clinicians, vol. 61, no. 2, pp. 69-90, 2011.

[4] GLOBOCAN, "Breast Cancer Estimated Incidence, Mortality and Prevalence Worldwide in 2012".

[5] R. Kumar, A. Sharma, and R. K. Tiwari, "Application of microarray in breast cancer: An overview," Journal of Pharmacy and Bioallied Sciences, vol. 4, no. 1, pp. 21-26, 2012.

[6] S. Banerji, K. Cibulskis, C. Rangel-Escareno et al., "Sequence analysis of mutations and translocations across breast cancer subtypes," Nature, vol. 486, no. 7403, pp. 405-409, 2012.

[7] A. López-Cortés, C. Echeverría, F. Oña-Cisneros et al., "Breast cancer risk associated with gene expression and genotype polymorphisms of the folate-metabolizing MTHFR gene: a casecontrol study in a high altitude Ecuadorian mestizo population," Tumor Biology, vol. 36, no. 8, pp. 6451-6461, 2015.

[8] M. R. G. Taylor, M. Špírek, K. R. Chaurasiya et al., "Rad51 paralogs remodel pre-synaptic Rad51 filaments to stimulate homologous recombination," Cell, vol. 162, no. 2, pp. 271-286, 2015.

[9] E. Honrado, A. Osorio, J. Palacios, and J. Benitez, "Pathology and gene expression of hereditary breast tumors associated with BRCA1, BRCA2 and CHEK2 gene mutations," Oncogene, vol. 25, no. 43, pp. 5837-5845, 2006.

[10] D. C. Koboldt, R. S. Fulton, M. D. McLellan et al., "Comprehensive molecular portraits of human breast tumours," Nature, vol. 490, no. 7418, pp. 61-70, 2012.

[11] D. Barh and M. Gunduz, "A Comprehensive Pan-Cancer Molecular Study of Gynecologic and Breast Cancers," Cancer Cell, 2018.

[12] D. Tamborero, C. Rubio-Perez, J. Deu-Pons, MP. Schroeder, A. Vivancos, and A. Rovira, "Cancer Genome Interpreter Annotates The Biological And Clinical Relevance Of Tumor Alterations," bioRxiv, 2017.

[13] B. Vanhaesebroeck and D. R. Alessi, "The PI3K-PDK1 connection: more than just a road to PKB," Biochemical Journal, vol. 346, part 3, pp. 561-576, 2000.

[14] D. Hanahan and R. A. Weinberg, "Hallmarks of cancer: the next generation," Cell, vol. 144, no. 5, pp. 646-674, 2011.

[15] S. Zhang and D. Yu, "PI(3)king apart PTEN's role in cancer," Clinical Cancer Research, vol. 16, no. 17, pp. 4325-4330, 2010.

[16] E. Dazert and M. N. Hall, "MTOR signaling in disease," Current Opinion in Cell Biology, vol. 23, no. 6, pp. 744-755, 2011.
[17] R. Zoncu, A. Efeyan, and D. M. Sabatini, "MTOR: from growth signal integration to cancer, diabetes and ageing," Nature Reviews Molecular Cell Biology, vol. 12, no. 1, pp. 21-35, 2011.

[18] J. Chen, P. Shao, Q. Cao et al., "Genetic variations in a PTEN/AKT/mTOR axis and prostate cancer risk in a Chinese population," PLoS ONE, vol. 7, no. 7, Article ID e40817, 2012.

[19] L.-Z. Liu, X.-D. Zhou, G. Qian, X. Shi, J. Fang, and B.$\mathrm{H}$. Jiang, "AKT1 amplification regulates cisplatin resistance in human lung cancer cells through the mammalian target of rapamycin/p70s6K1 pathway," Cancer Research, vol. 67, no. 13, pp. 6325-6332, 2007.

[20] L. S. Faried, A. Faried, T. Kanuma et al., "Expression of an activated mammalian target of rapamycin in adenocarcinoma of the cervix: A potential biomarker and molecular target therapy," Molecular Carcinogenesis, vol. 47, no. 6, pp. 446-457, 2008.

[21] X. Yang, M. Fraser, U. M. Moll, A. Basak, and B. K. Tsang, "Aktmediated cisplatin resistance in ovarian cancer: modulation of p53 action on caspase-dependent mitochondrial death pathway," Cancer Research, vol. 66, no. 6, pp. 3126-3136, 2006.

[22] V. Shanthi, R. Rajasekaran, and K. Ramanathan, "Computational identification of significant missense mutations in AKT1 gene," Cell Biochemistry and Biophysics, vol. 70, no. 2, pp. 957965, 2014.

[23] C. Parikh, V. Janakiraman, W.-I. Wu et al., "Disruption of PHkinase domain interactions leads to oncogenic activation of AKT in human cancers," Proceedings of the National Acadamy of Sciences of the United States of America, vol. 109, no. 47, pp. 19368-19373, 2012.

[24] S. Dimmeler, I. Fleming, B. Fisslthaler, C. Hermann, R. Busse, and A. M. Zeiher, "Activation of nitric oxide synthase in endothelial cells by Akt- dependent phosphorylation," Nature, vol. 399, no. 6736, pp. 601-605, 1999.

[25] O. N. Ozes, L. D. Mayo, J. A. Gustin, S. R. Pfeffer, L. M. Pfeffer, and D. B. Donner, "NF- $\kappa$ B activation by tumour necrosis factor requires tie Akt serine-threonine kinase," Nature, vol. 401, no. 6748, pp. 82-85, 1999.

[26] I. Mende, S. Malstrom, P. N. Tsichlis, P. K. Vogt, and M. Aoki, "Oncogenic transformation induced by membrane-targeted Akt2 and Akt3," Oncogene, vol. 20, no. 32, pp. 4419-4423, 2001.

[27] L. Wei, Y. Yang, and Q. Yu, "Tyrosine kinase-dependent, phosphatidylinositol 3/-kinase, and mitogen-activated protein kinase-independent signaling pathways prevent lung adenocarcinoma cells from anoikis," Cancer Research, vol. 61, no. 6, pp. 2439-2444, 2001.

[28] M. A. T. Hildebrandt, H. Yang, M.-C. Hung et al., "Genetic variations in the PI3K/PTEN/AKT/mTOR pathway are associated with clinical outcomes in esophageal cancer patients treated with chemoradiotherapy," Journal of Clinical Oncology, vol. 27, no. 6, pp. 857-871, 2009.

[29] K. Pfisterer, A. Fusi, K. Klinghammer, M. Knödler, A. Nonnenmacher, and U. Keilholz, "PI3K/PTEN/AKT/mTOR polymorphisms: Association with clinical outcome in patients with head and neck squamous cell carcinoma receiving cetuximabdocetaxel," Head \& Neck, vol. 37, no. 4, pp. 471-478, 2015.

[30] M. J. Kim, H.-G. Kang, S. Y. Lee et al., "AKT1 polymorphisms and survival of early stage non-small cell lung cancer," Journal of Surgical Oncology, vol. 105, no. 2, pp. 167-174, 2012.

[31] S. Rodriguez, T. R. Gaunt, and I. N. M. Day, "Hardy-Weinberg equilibrium testing of biological ascertainment for Mendelian randomization studies," American Journal of Epidemiology, vol. 169, no. 4, pp. 505-514, 2009. 
[32] K. Michailidou, P. Hall, and A. Gonzalez-Neira, "Large-scale genotyping identifies 41 new loci associated with breast cancer risk," Nature Genetics, vol. 45, no. 4, pp. 353-361, 2013.

[33] D. F. Easton, K. A. Pooley, A. M. Dunning et al., "Genome-wide association study identifies novel breast cancer susceptibility loci," Nature, vol. 447, no. 7148, pp. 1087-1093, 2007.

[34] A. Siddiq, F. J. Couch, G. K. Chen et al., "A meta-analysis of genome-wide association studies of breast cancer identifies two novel susceptibility loci at 6q14 and 20q11," Human Molecular Genetics, vol. 21, no. 24, pp. 5373-5384, 2012.

[35] L. J. Engle, C. L. Simpson, and J. E. Landers, "Using highthroughput SNP technologies to study cancer," Oncogene, vol. 25, no. 11, pp. 1594-1601, 2006.

[36] L. Fejerman, N. Ahmadiyeh, D. Hu et al., "Genome-wide association study of breast cancer in Latinas identifies novel protective variants on 6q25," Nature Communications, vol. 5, article no. 5260, 2014.

[37] D. A. Altomare and J. R. Testa, "Perturbations of the AKT signaling pathway in human cancer," Oncogene, vol. 24 , no. 50 , pp. 7455-7464, 2005.

[38] K. A. West, S. S. Castillo, and P. A. Dennis, "Activation of the PI3K/Akt pathway and chemotherapeutic resistance," Drug Resistance Updates, vol. 5, no. 6, pp. 234-248, 2002.

[39] J. D. Carpten, A. L. Faber, C. Horn et al., "A transforming mutation in the pleckstrin homology domain of AKT1 in cancer," Nature, vol. 448, no. 7152, pp. 439-444, 2007.

[40] Y. Yu, R. E. Savage, S. Eathiraj et al., "Targeting AKT1-E17K and the PI3K/AKT pathway with an allosteric AKT inhibitor, ARQ 092," PLoS ONE, vol. 10, no. 10, Article ID 0140479, 2015.

[41] K. Stemke-Hale, A. M. Gonzalez-Angulo, A. Lluch et al., "An integrative genomic and proteomic analysis of PIK3CA, PTEN, and AKT mutations in breast cancer," Cancer Research, vol. 68, no. 15, pp. 6084-6091, 2008.

[42] M. S. Kim, E. G. Jeong, N. J. Yoo, and S. H. Lee, "Mutational analysis of oncogenic AKT E17K mutation in common solid cancers and acute leukaemias," British Journal of Cancer, vol. 98, no. 9, pp. 1533-1535, 2008.

[43] Y. Wang, L. Lin, H. Xu et al., "Genetic variants in AKT1 gene were associated with risk and survival of OSCC in Chinese Han Population," Journal of Oral Pathology \& Medicine, vol. 44, no. 1, pp. 45-50, 2015.

[44] A. López-Cortés, G. Jaramillo-Koupermann, and M. J. Muñoz, "Genetic polymorphisms in MTHFR (C677T, A1298C), MTR (A2756G) and MTRR (A66G) genes associated with pathological characteristics of prostate cancer in the ecuadorian population," The American Journal of the Medical Sciences, vol. 346, no. 6, pp. 447-454, 2013.

[45] A. López-Cortés, A. Cabrera-Andrade, C. Salazar-Ruales et al., "Genotyping the high altitude mestizo ecuadorian population affected with prostate cancer," BioMed Research International, vol. 2017, 2017.

[46] C. Paz-y-Miño, A. López-Cortés, M. J. Muñoz, A. Cabrera, B. Castro, and M. E. Sánchez, "Incidence of the L858R and G719S mutations of the epidermal growth factor receptor oncogene in an Ecuadorian population with lung cancer," Cancer Genetics and Cytogenetics, vol. 196, no. 2, pp. 201-203, 2010.

[47] C. Paz-y-Miño, M. J. Muñoz, A. López-Cortés et al., "Frequency of polymorphisms pro198leu in GPX-1 gene and ile58thr in MnSOD gene in the altitude ecuadorian population with bladder cancer," Oncology Research : Featuring Preclinical and Clinical Cancer Therapeutics, vol. 18, no. 8, pp. 395-400, 2010.
[48] L. Quinones, M. Lavanderos, J. Cayun et al., "Perception of the Usefulness of Drug/Gene Pairs and Barriers for Pharmacogenomics in Latin America," Current Drug Metabolism, vol. 15, no. 2, pp. 202-208, 2014.

[49] A. López-Cortés, S. Guerrero, M. Redal, A. Alvarado, and L. Quiñones, "State of Art of Cancer Pharmacogenomics in Latin American Populations," International Journal of Molecular Sciences, vol. 18, no. 6, p. 639, 2017. 


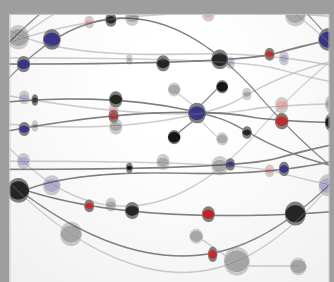

The Scientific World Journal
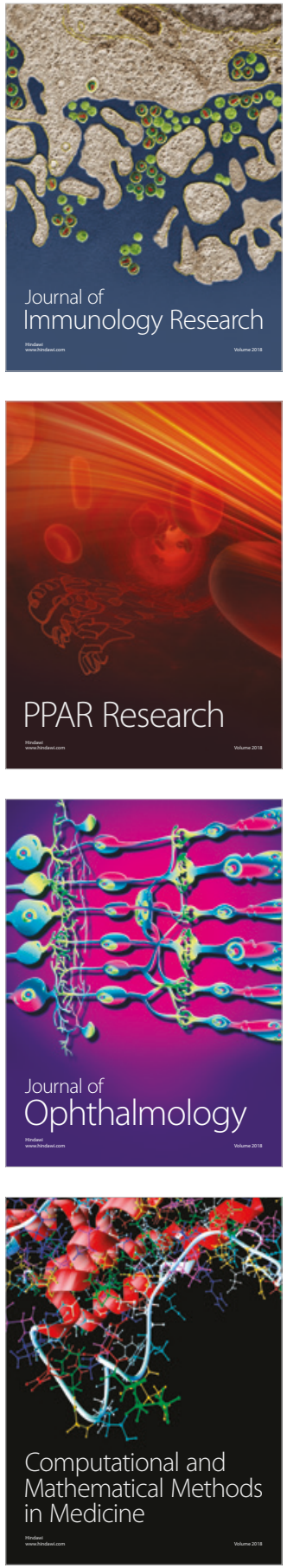

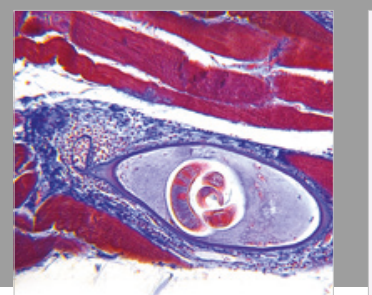

Gastroenterology Research and Practice

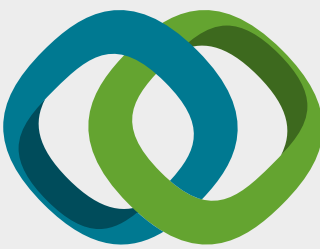

\section{Hindawi}

Submit your manuscripts at

www.hindawi.com
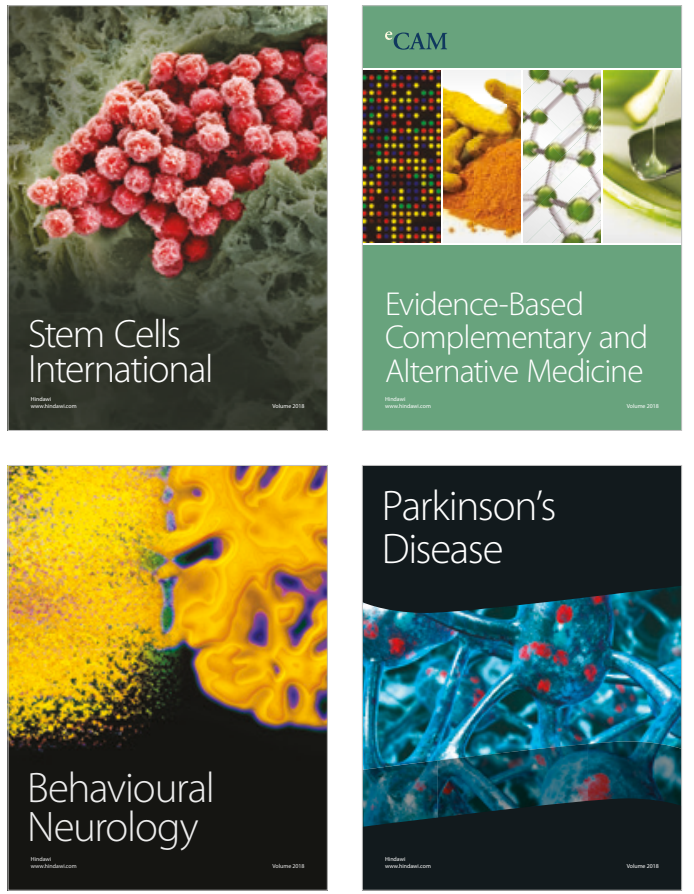

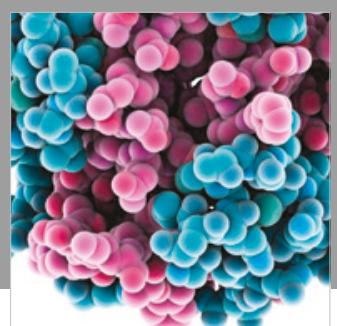

ournal of

Diabetes Research

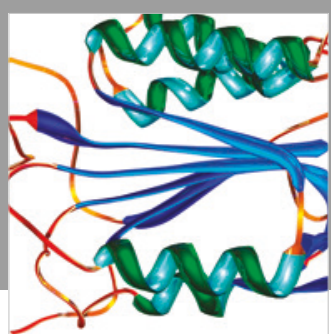

Disease Markers
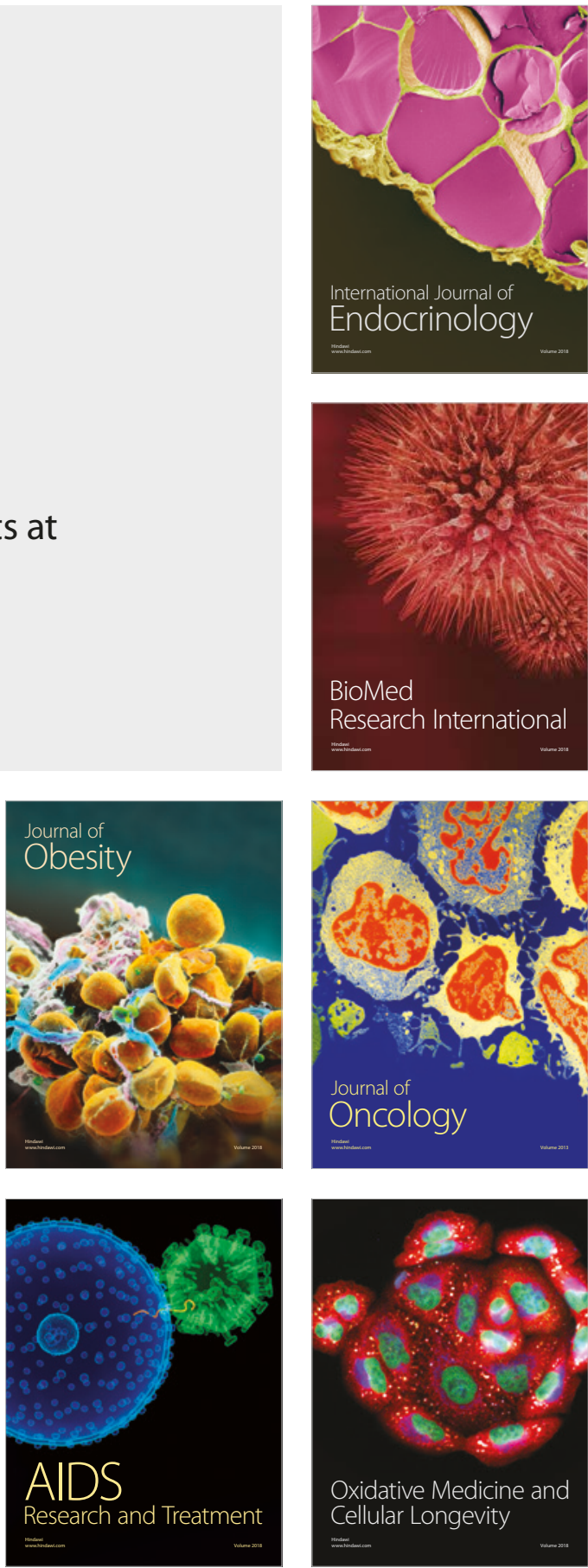